\title{
Nasofacial Anthropometric Study among University Students of Three Races in Malaysia
}

\author{
Mar Mar Wai, ${ }^{1}$ San San Thwin, ${ }^{1}$ Tahamida Yesmin, ${ }^{1}$ Aqlan Ahmad, ${ }^{2}$ Atina Shahida Adnan, \\ Auni Azrawati Hassan, ${ }^{2}$ Nabilah Ahmad, ${ }^{2}$ and Nurul Izzati Zakariah ${ }^{2}$ \\ ${ }^{1}$ Anatomy Department, UniKL Royal College of Medicine, No. 3, Jalan Greentown, 30450 Ipoh, Perak, Malaysia \\ ${ }^{2}$ MBBS Programme, UniKL Royal College of Medicine, No. 3, Jalan Greentown, 30450 Ipoh, Perak, Malaysia \\ Correspondence should be addressed to Mar Mar Wai; dmarmarwai@gmail.com
}

Received 18 October 2014; Accepted 26 November 2014

Academic Editor: Huayue Chen

Copyright (C) 2015 Mar Mar Wai et al. This is an open access article distributed under the Creative Commons Attribution License, which permits unrestricted use, distribution, and reproduction in any medium, provided the original work is properly cited.

\begin{abstract}
Objective. Anthropometric data of the nasofacial dimensions is vital in nasofacial surgery, forensics medicine, and diagnostic comprehension. Nasofacial anthropometry is "ethnic sensitive" and has distinct sexual dimorphism. This study is aimed to observe the variations of length and width of face and nose among university students of three races in Ipoh, Malaysia. Material and Method. A cross-sectional study was done on 200 college students aged between 18 and 21 years, using convenient sampling method. The facial length and width and nasal length and width were measured. The data were analysed using the SPSS software. Result. The mean facial index of Malay subjects showed $88.82 \pm 6.63$ with nasal index of $81.00 \pm 7.48$, showing dominance of the leptoprosopic face type and mesorrhine nose type. Chinese subjects showed facial index and nasal index of $85.65 \pm 6.50$ and $79.56 \pm 8.62$, respectively, having mesoprosopic face type and mesorrhine nose type. Indian students had facial index of $92.57 \pm 7.19$ and nasal index of $76.27 \pm$ 7.39 , having leptoprosopic face type and mesorrhine nose type. The differences in means of facial and nasal indices between the three races were statistically significant $(P<0.005)$. Conclusion. The result of our study has confirmed that there was sexual dimorphism of facial and nasal parameters and also significant differences of facial and nasal indices amongst the three Malaysian race groups.
\end{abstract}

\section{Introduction}

Anthropometry comes from a Greek word "Anthropos" which means human and "metron" which means measure [1]. According to the WHO, the anthropometry is an inexpensive and noninvasive technique for assessing the size, proportions, and composition of the human body. Nasofacial anthropometry is a specific component of the anthropometric field that focuses on the facial and nasal regions which is also vital for sex determination, forensics uses, quantifying nasofacial dysmorphology, facial surgery, and diagnostic comprehension. By using accurate anthropometric measurements in craniofacial region, we can treat and reconstruct congenital or posttraumatic facial disfigurements successfully [2].

Anthropometry of any parts of the body varies between individuals and among races. The face and the nose are important physiognomic features in humans. Face and nose are developed from frontonasal prominences, nasal prominences, and maxillary and mandibular prominences and final characteristic of the face depends mainly on the changes in the proportion and position of these facial components, Moore [3]. The growth and development of humans are affected by many factors including geocological, biological, geographical, racial, gender, and age factors, Jahanshahi et al. [4] and Kurnia et al. [5].

Knowledge of the absolute and relative variability in the size and shape of the human body is crucial to study human growth, population variation, and medicolegal identification in forensics as well as in the optimization of instruments such as respirators, gas and dust masks, and military helmets [1].

In Malaysia, research studies on facial index and nose index in different races precisely in young adult are very few. Our research is specific in the measurement of facial width, facial length, nasal width, and nasal length among different races in Malaysia. The three major races in Malaysia are Malay, Chinese, and Indian. These races are very distinguishable in various features including their physical traits, religions, and cultures as well as many more features. 


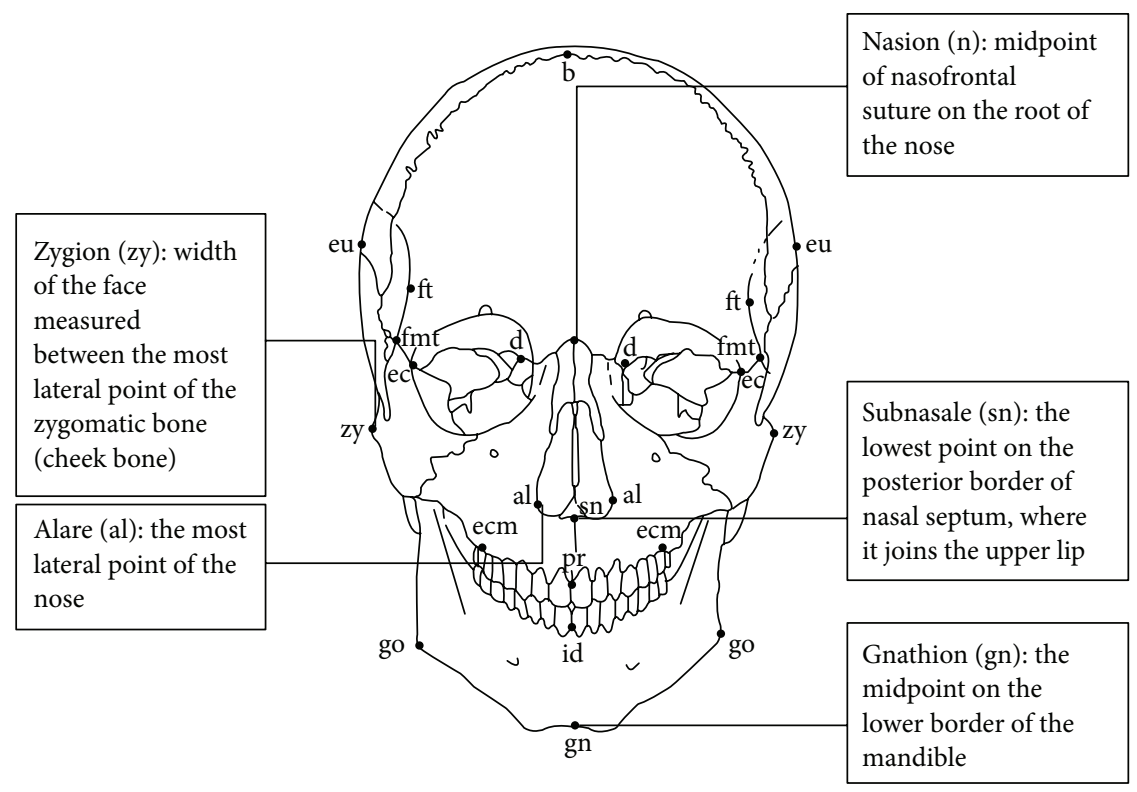

FIGURE 1: The landmarks of nasion (n), gnathion (gn), zygion (zy), subnasale (sn), and alare (al).

According to Naini [6], the classification of anatomical face and nose type is shown in Table 1.

Anthropometric study in Malay and Malaysian Indian was done by Ngeow and Aljunid (2009) on the parameters of the face and head regions, Ngeow [7, 8], but not extensive enough. Therefore, we aimed at studying anthropometry of nasofacial region in the Malaysian population.

\section{Material and Method}

A cross-sectional study on the anthropometry of facial length, facial width, nasal length, and nasal width was done on three races among young Malaysian in Ipoh, Perak. The study was done mainly around the UniKL-RCMP area, focusing on college students. A total of 200 young adults consisting of 120 Malay, 40 Chinese, and 40 Indians were taken. 100 males and 100 females were taken. The age group is 18 to 21 . Convenient sampling method was used in determining the sample size.

The anthropometric data was collected by measuring the distance between facial and nasal landmarks as provided by Farkas et al. (2005) in Farkas craniofacial anthropometry system [2]. A 12 -inch $(0.003 \mathrm{~mm})$ fast display caliper series EC05 (ID: 111-103-20g) was used in data collection.

The subjects were asked to sit with their head held out straight in anatomical position. They were explained verbally about the measurement procedures and precautionary steps. Facial height is measured as a straight distance between nasion (n) and gnathion (gn), while facial width is the distance between zygion (zy) and zygion (Figure 1). Consider

$$
\text { Facial index }=\frac{\text { facial length }}{\text { facial width }} \times 100 \text {. }
$$

Nasal index is calculated by using the formula below.
TABLE 1

\begin{tabular}{lc}
\hline Face type & Facial index \\
\hline Hypereuryprosopic (very broad, short face) & $\leq 78.9$ \\
Euryprosopic (broad, short face) & $79.0-83.9$ \\
Mesoprosopic (normoprosopic: average face) & $84.0-87.9$ \\
Leptoprosopic (tall, narrow face) & $88.0-92.9$ \\
Hyperleptoprosopic (very tall, narrow face) & $\geq 93.0$ \\
\hline Nose type & Nasal index \\
\hline Hyperleptorrhine (excessively tall and narrow) & $\leq 54.9$ \\
Leptorrhine (tall and narrow) & $55.0-69.9$ \\
Mesorrhine (medium) & $70.0-84.9$ \\
Platyrrhine (broad and flat) & $85.0-99.9$ \\
Hyperplatyrrhine (excessively broad and flat) & $\geq 100.0$ \\
\hline
\end{tabular}

As for the nasal indices, nasal length is measured as the distance between nasion ( $\mathrm{n}$ ) and subnasale (sn), while nasal width is the interalar distance (al-al). All these measurements were in millimetre and were then recorded in tables provided in the questionnaire. The average for all measurements was calculated, as well as the facial index and nasal index. Facial index is calculated by using the following formula:

$$
\text { Nasal index }=\frac{\text { nasal width }}{\text { nasal length }} \times 10 \text {. }
$$

The data was further analysed statistically to determine the mean, standard deviation, and significance level ( $P$ value).

ANOVA test and $t$-test were done for data analysis using SPSS 17.0 software to find the facial and nasal indices, means, and standard deviations for all parameters and the $P$ value. 
TABLE 2: Mean $( \pm \mathrm{SD})$ of the facial length $(\mathrm{FL})$, facial width $(\mathrm{FW})$, nasal length $(\mathrm{NL})$, and nasal width (NW) of male and female in two age groups.

\begin{tabular}{|c|c|c|c|c|c|c|c|c|}
\hline \multirow[b]{2}{*}{ Race } & \multirow[b]{2}{*}{$\begin{array}{l}\text { Anthropometric } \\
\text { variables }\end{array}$} & \multicolumn{3}{|c|}{ Age group 18-19 $(n=100)$} & \multicolumn{3}{|c|}{ Age group 20-21 $(n=100)$} & \multirow[b]{2}{*}{$P$ value } \\
\hline & & $\begin{array}{c}\text { Male } \\
\text { Mean }( \pm S D)\end{array}$ & $\begin{array}{c}\text { Female } \\
\text { Mean }( \pm S D)\end{array}$ & $P$ value & $\begin{array}{c}\text { Male } \\
\text { Mean }( \pm S D)\end{array}$ & $\begin{array}{c}\text { Female } \\
\text { Mean }( \pm S D)\end{array}$ & $P$ value & \\
\hline \multirow{4}{*}{ Malay } & $\mathrm{FL}$ & $115.24( \pm 5.87)$ & $106.63( \pm 3.96)$ & 0.000 & $118.13( \pm 6.52)$ & $107.39( \pm 4.38)$ & 0.000 & 0.166 \\
\hline & FW & $131.73( \pm 9.74)$ & $115.06( \pm 4.70)$ & 0.000 & $137.33( \pm 7.11)$ & $121.94( \pm 7.06)$ & 0.000 & 0.002 \\
\hline & NL & $51.79( \pm 3.42)$ & $45.79( \pm 2.75)$ & 0.000 & $50.15( \pm 4.34)$ & $45.61( \pm 3.28)$ & 0.000 & 0.260 \\
\hline & NW & $40.50( \pm 2.39)$ & $36.36( \pm 1.96)$ & 0.000 & $40.91( \pm 2.78)$ & $38.09( \pm 3.20)$ & 0.000 & 0.067 \\
\hline \multirow{4}{*}{ Chinese } & $\mathrm{FL}$ & $119.62( \pm 8.20)$ & $110.10( \pm 5.32)$ & 0.006 & $115.48( \pm 5.50)$ & $111.19( \pm 6.53)$ & 0.129 & 0.515 \\
\hline & FW & $137.89( \pm 5.27)$ & $128.46( \pm 9.60)$ & 0.014 & $136.35( \pm 8.19)$ & $131.90( \pm 11.39)$ & 0.329 & 0.751 \\
\hline & $\mathrm{NL}$ & $51.76( \pm 5.55)$ & $45.68( \pm 4.22)$ & 0.013 & $50.14( \pm 6.02)$ & $47.29( \pm 3.06)$ & 0.198 & 0.996 \\
\hline & NW & $40.20( \pm 2.70)$ & $36.60( \pm 1.90)$ & 0.003 & $39.42( \pm 2.20)$ & $37.48( \pm 3.29)$ & 0.138 & 0.961 \\
\hline \multirow{4}{*}{ Indians } & $\mathrm{FL}$ & $118.08( \pm 6.70)$ & $108.79( \pm 4.83)$ & 0.002 & $119.15( \pm 6.89)$ & $108.69( \pm 3.25)$ & 0.000 & 0.832 \\
\hline & FW & $131.17( \pm 7.63)$ & $118.91( \pm 8.18)$ & 0.003 & $127.38( \pm 9.39)$ & $115.75( \pm 7.11)$ & 0.006 & 0.278 \\
\hline & $\mathrm{NL}$ & $51.32( \pm 3.44)$ & $48.00( \pm 3.09)$ & 0.036 & $51.36( \pm 4.25)$ & $47.48( \pm 3.29)$ & 0.035 & 0.849 \\
\hline & NW & $39.58( \pm 1.61)$ & $35.70( \pm 3.09)$ & 0.002 & $40.13( \pm 3.65)$ & $35.22( \pm 2.42)$ & 0.002 & 0.978 \\
\hline
\end{tabular}

TABLE 3: Mean $( \pm S D)$ of the length and width of face and nose of young Malay, Chinese, and Indian adults (combined age groups) in Ipoh.

\begin{tabular}{|c|c|c|c|c|c|c|c|c|c|c|c|c|c|}
\hline \multirow{3}{*}{ Variable } & \multirow{2}{*}{\multicolumn{4}{|c|}{$\begin{array}{c}\text { Malay }(n=120) \\
\text { Mean }( \pm S D)\end{array}$}} & \multirow{2}{*}{\multicolumn{4}{|c|}{$\begin{array}{c}\text { Chinese }(n=40) \\
\text { Mean }( \pm S D)\end{array}$}} & \multirow{2}{*}{\multicolumn{4}{|c|}{$\begin{array}{c}\text { Indian }(n=40) \\
\text { Mean }( \pm S D)\end{array}$}} & \multirow{3}{*}{$P$ value } \\
\hline & & & & & & & & & & & & & \\
\hline & Male & Female & $P$ value & Both & Male & Female & $P$ value & Both & Male & Female & $P$ value & Both & \\
\hline FL & $\begin{array}{c}116.68 \\
( \pm 6.32)\end{array}$ & $\begin{array}{c}107.01 \\
( \pm 4.15)\end{array}$ & 0.000 & $\begin{array}{c}111.84 \\
( \pm 7.21)\end{array}$ & $\begin{array}{c}117.55 \\
( \pm 7.12)\end{array}$ & $\begin{array}{c}110.64 \\
( \pm 5.82)\end{array}$ & 0.002 & $\begin{array}{l}114.10 \\
( \pm 7.31)\end{array}$ & $\begin{array}{c}118.61 \\
( \pm 6.64)\end{array}$ & $\begin{array}{l}108.72 \\
( \pm \mathbf{4 . 0 1})\end{array}$ & 0.000 & $\begin{array}{c}113.67 \\
( \pm 7.38)\end{array}$ & 0.149 \\
\hline FW & $\begin{array}{c}134.53 \\
( \pm \mathbf{8 . 9 2})\end{array}$ & $\begin{array}{c}118.50 \\
( \pm 6.88)\end{array}$ & 0.000 & $\begin{array}{c}126.51 \\
( \pm \mathbf{1 1 . 3 0})\end{array}$ & $\begin{array}{c}137.12 \\
( \pm 6.75)\end{array}$ & $\begin{array}{c}130.18 \\
( \pm \mathbf{1 0 . 4 1})\end{array}$ & 0.017 & $\begin{array}{c}133.65 \\
( \pm 9.34)\end{array}$ & $\begin{array}{c}129.27 \\
( \pm \mathbf{8 . 5 5})\end{array}$ & $\begin{array}{c}117.33 \\
( \pm 7.63)\end{array}$ & 0.000 & $\begin{array}{c}123.30 \\
( \pm \mathbf{1 0 . 0 3})\end{array}$ & 0.000 \\
\hline NL & $\begin{array}{c}50.97 \\
( \pm 3.96)\end{array}$ & $\begin{array}{c}45.70 \\
( \pm 3.00)\end{array}$ & 0.000 & $\begin{array}{c}48.34 \\
( \pm 4.39)\end{array}$ & $\begin{array}{c}50.95 \\
( \pm 5.69)\end{array}$ & $\begin{array}{c}46.48 \\
( \pm 3.68)\end{array}$ & 0.006 & $\begin{array}{c}48.71 \\
( \pm 5.25)\end{array}$ & $\begin{array}{c}51.34 \\
( \pm 2.76)\end{array}$ & $\begin{array}{c}47.74 \\
( \pm 3.12)\end{array}$ & 0.002 & $\begin{array}{c}49.54 \\
( \pm 3.87)\end{array}$ & 0.338 \\
\hline NW & $\begin{array}{c}40.70 \\
( \pm 2.58)\end{array}$ & $\begin{array}{c}37.23 \\
( \pm 2.77)\end{array}$ & 0.000 & $\begin{array}{c}38.96 \\
( \pm 3.19)\end{array}$ & $\begin{array}{c}39.81 \\
( \pm 2.43)\end{array}$ & $\begin{array}{c}37.04 \\
( \pm \mathbf{2 . 6 5})\end{array}$ & 0.001 & $\begin{array}{c}38.43 \\
( \pm 2.87)\end{array}$ & $\begin{array}{c}39.85 \\
( \pm 2.76)\end{array}$ & $\begin{array}{c}35.46 \\
( \pm 2.71)\end{array}$ & 0.000 & $\begin{array}{c}37.66 \\
( \pm \mathbf{3 . 5 0})\end{array}$ & 0.078 \\
\hline
\end{tabular}

\section{Inclusion and Exclusion Criteria}

Individuals with mixed racial parentage are excluded. Individuals that have had facial trauma, septoplasty, or septorhinoplasty, craniofacial abnormalities, and other minor ethnics in Malaysia, such as Iban, Bidayuh, are also excluded.

\section{Result}

The facial and nasal parameters between age groups, genders, and races had been measured and recorded.

According to Table 2, the gender difference in Malay was significant for all the parameters, with males having a higher mean value $(P<0.05)$.

The gender difference in Chinese and Indians was significant for all the parameters, with males having a higher mean value $(P<0.05)$.

Table 3 showed that in combined age group all the parameters showed sexual dimorphism. The facial width is the only parameter that showed significant difference $(P<$ $0.05)$ in between three races.

In Table 4, facial index of Malay young adults showed $88.82 \pm 6.63$ with nasal index of $81.00 \pm 7.48$, indicating the dominance of the leptoprosopic face type and mesorrhine nose type. Chinese young adults revealed facial index and nasal index of $85.65 \pm 6.50$ and $79.56 \pm 8.62$, respectively. They had mesoprosopic face type and mesorrhine nose type.

Indian young adults had facial index of $92.57 \pm 7.19$ and nasal index of $76.27 \pm 7.39$, implying leptoprosopic face type and mesorrhine nose type among Indian young adults. The differences in means of facial and nasal indices between the three races were statistically significant $(P<0.05)$ as shown in Table 4.

Overall, the difference in the mean value of facial index between male and female of all three races combined was statistically significant. Nasal index was not statistically significant between males and females $(P>0.05)$. Between the three races, both facial and nasal indices were significantly different (Table 4).

\section{Discussion}

Gender difference was statistically significant for all facial and nasal parameters for Malay, Chinese, and Indian young adults $(P<0.05)$. This showed that there was sexual dimorphism in 
TABLE 4: Mean $( \pm S D)$ of the facial and nasal indices of Malay, Chinese, and Indian young adults in Ipoh.

\begin{tabular}{|c|c|c|c|c|c|c|c|c|c|c|c|c|c|}
\hline \multirow{3}{*}{ Variable } & \multicolumn{4}{|c|}{ Malay $(n=120)$} & \multicolumn{4}{|c|}{ Chinese $(n=40)$} & \multicolumn{4}{|c|}{ Indian $(n=40)$} & \multirow{3}{*}{$P$ value } \\
\hline & & Mean & $( \pm \mathrm{SD})$ & & & Mean & $( \pm \mathrm{SD})$ & & & Mean & $( \pm \mathrm{SD})$ & & \\
\hline & Male & Female & $P$ value & Both & Male & Female & $P$ value & Both & Male & Female & $P$ value & Both & \\
\hline Facial index & $\begin{array}{c}87.04 \\
( \pm 6.63)\end{array}$ & $\begin{array}{c}90.59 \\
( \pm 6.20)\end{array}$ & 0.003 & $\begin{array}{c}88.82 \\
( \pm 6.63)\end{array}$ & $\begin{array}{c}85.90 \\
( \pm 6.35)\end{array}$ & $\begin{array}{c}85.40 \\
( \pm 6.80)\end{array}$ & 0.811 & $\begin{array}{c}85.65 \\
( \pm 6.50)\end{array}$ & $\begin{array}{c}92.14 \\
( \pm 8.13)\end{array}$ & $\begin{array}{c}92.99 \\
( \pm 6.30)\end{array}$ & 0.303 & $\begin{array}{c}92.57 \\
( \pm 7.19)\end{array}$ & 0.000 \\
\hline Nasal index & $\begin{array}{c}80.25 \\
( \pm 7.24) \\
\end{array}$ & $\begin{array}{c}81.77 \\
( \pm 7.69)\end{array}$ & 0.268 & $\begin{array}{c}81.00 \\
( \pm 7.48) \\
\end{array}$ & $\begin{array}{c}78.96 \\
( \pm 8.83) \\
\end{array}$ & $\begin{array}{c}80.17 \\
( \pm 8.59)\end{array}$ & 0.662 & $\begin{array}{c}79.56 \\
( \pm 8.62) \\
\end{array}$ & $\begin{array}{c}77.92 \\
( \pm 6.63) \\
\end{array}$ & $\begin{array}{c}74.62 \\
( \pm 7.90)\end{array}$ & 0.437 & $\begin{array}{c}76.27 \\
( \pm 7.39) \\
\end{array}$ & 0.004 \\
\hline
\end{tabular}

Malaysian population. Males had higher mean value than the females (Table 2).

The study of Omotoso et al. (2011) showed significant differences in the mean morphological and total facial and nasal length and nasal width across the gender, Omotoso [9], which was comparable to our study.

According to standard classification, a facial index higher than 85 is categorized as leptoprosopic (tall and narrow face), while facial index below 77 is categorized as euryprosopic (broad and short face). Intermediate facial index indicates mesoprosopic type, Naini [6].

Shetti et al. [10] stated that Malaysian and Indian medical students had mesoprosopic type of face and comparison between Indian and Malaysian subjects indicated that Indians (both sexes together) had a higher (87.04) mean facial index than Malaysians (86.76). This difference showed that Malaysians had slightly broader faces when compared to Indians. However, this difference was not statistically significant.

Our study showed that Malay young adults had a facial index of $88.82 \pm 6.63$ with nasal index of $81.00 \pm 7.48$, indicating the dominance of the leptoprosopic face type and mesorrhine nose type. Chinese young adults had a facial and nasal index of $85.65 \pm 6.50$ and $79.56 \pm 8.62$, respectively, with a mesoprosopic face type and mesorrhine nose type. Indian young adults had facial index of $92.57 \pm 7.19$ and nasal index of $76.27 \pm 7.39$, which implied leptoprosopic face type and mesorrhine nose type. The difference of facial indices across gender was found to be significant in Malay but not in other races. The differences of nasal indices across gender were not significant in all three races. The differences in mean of facial and nasal indices between the three races were statistically significant $(P<0.05)$.

According to Omotso et al. (2011), the mean facial and nasal indices also showed a significant variation across gender with higher values observed among the males than the females. The overall facial and nasal indices were 86.93 and 97.32, respectively, which implied the prevalence of the mesoprosopic face type and platyrrhine nose type among the Bini tribe in Nigeria [9].

According to Kurnia et al. (2012), the common face type among Chinese in Indonesia was leptoprosopic type in male and mesoprosopic type in female. This finding was similar to the facial type found in young Malay and Indian in our study [5]. Facial type tended to be longer in male because the growth rate in men was greater.
Several studies have indicated the racial and ethnic differences in nasal index amongst different populations [11]. Most Caucasians are leptorrhine having long and narrow nose with nasal index of 69.9 or less. The Indo-Aryan was also similar to the Europeans, possessing a fine nose [12]. Jingpo people in China are mesorrhine [13]. Indo-African [12] and Afro-American [14] people have platyrrhine nose type (12) [10].

Kaushal et al. [15] stated that nasal index of a race appears to be markedly related to climate; the narrow and long noses favored cold and dry climate, as there was more surface area for warming the air, whereas flat and broad nose types were seen in warm and moist climate, as a consequence of natural selection in human evolution [16].

Staka et al. (2012) stated that males have a significantly higher nasal index than females $(P<0.001)$, which confirms the existence of sexual dimorphism in nasal parameters among Kosovo Albanian population [17].

Heidari et al. stated that the most common type of nose in the Iranian population (Sistani and Baluch groups) was the leptorrhine type (fine nose) and most common face type is the leptoprosopic type. They speculated that the shape of the nose in both ethnicities in this region of Iran had been adapted to the environment [18].

\section{Conclusion}

The dominant face shape was leptoprosopic for the Malays and Indians, while it was mesoprosopic in Chinese. The dominant nose type in all three races was the mesorrhine type which was similar to the findings of other Asian races. Anthropometric data of the face and nose obtained would be useful for sex determination, forensics medicine, identifying nasofacial dysmorphology, and reconstructive facial and nasal surgeries. More studies are needed in various fields of anthropometry within the Malaysian population to meet the demand in the medical and surgical fields.

\section{Conflict of Interests}

The authors declare that there is no conflict of interests regarding the publication of this paper.

\section{References}

[1] N. Khan, V. Leela, and G. Annavarapu, "A study of craniofacial anthropometrics in hyderabad (Deccan)-and a review of 
literature," Journal of Medical \& Allied Sciences, vol. 2, no. 2, pp. 54-57, 2012.

[2] L. G. Farkas, M. J. Katic, and C. R. Forrest, "International anthropometric study of facial morphology in various ethnic groups/races," The Journal of Craniofacial Surgery, vol. 16, no. 4, pp. 615-646, 2005.

[3] K. L. Moore, Before We are Born: Essential of Embryology and Birth Defects, San Diego, Calif, USA, Elsevier Science, 6th edition, 2003.

[4] M. Jahanshahi, M. J. Golalipour, and K. Heidari, "The effect of ethnicity on facial anthropometry in Northern Iran," Singapore Medical Journal, vol. 49, no. 11, pp. 940-943, 2008.

[5] C. Kurnia, S. Susiana, and W. Husin, "Facial indices in chinese ethnic students aged 20-22," Journal of Dentistry Indonesia, vol. 19, no. 1, pp. 1-4, 2012.

[6] F. Naini, "Facial aesthetic analysis," in Facial Aesthetics, F. Naini, Ed., pp. 123-237, Blackwell Publishing, London, UK, 2011.

[7] W. C. Ngeow and S. T. Aljunid, "Craniofacial anthropometric norms of Malays," Singapore Medical Journal, vol. 50, no. 5, pp. 525-528, 2009.

[8] W. C. Ngeow and S. T. Aljunid, "Craniofacial anthropometric norms of Malaysian Indians," Indian Journal of Dental Research, vol. 20, no. 3, pp. 313-319, 2009.

[9] D. R. Omotoso, O. O. Oludiran, and C. L. Sakpa, "Nasofacial anthropometry of adult Bini tribe in Nigeria," African Journal of Biomedical Research, vol. 14, no. 3, pp. 219-221, 2011.

[10] V. R. Shetti, S. R. Pai, G. K. Sneha, C. Gupta, and P. Chethan, "Study of prosopic (Facial) index of Indian and Malaysian students," International Journal of Morphology, vol. 29, no. 3, pp. 1018-1021, 2011.

[11] G. S. Oladipo, A. O. Olabiyi, A. A. Oremosu, and C. C. Noronha, "Nasal indices among major ethnic groups in southern Nigeria," Academic Journals, Scientific Research and Essay, vol. 2, no. 1, pp. 020-022, 2007.

[12] C. Z. Sparks and R. L. Jantz, "A reassessment of human cranial plasticity: boas revisited," Proceedings of the National Academy of Sciences of the United States of America, vol. 99, no. 23, pp. 14636-14639, 2002.

[13] B. Xu, Y. Wang, J. Ma, M. Li, and L. Xu, “A computer-aid study on the craniofacial features of archang race in Yunnan province of China," Huaxi Kouqiang Yixue Zazhi, vol. 19, no. 6, pp. 394396, 2001.

[14] F. A. Ofodile, "Nasal bones and pyriform apertures in blacks," Annals of Plastic Surgery, vol. 32, no. 1, pp. 21-26, 1994.

[15] S. Kaushal, V. V. G. Patnaik, and P. Kaur, "Somatometric analysis of nasal morphology in the endogamous groups of Punjab," Human Biology Review, vol. 2, no. 1, 2013.

[16] G. S. Oladipo, M. A. Eroje, and H. B. Fahwehinmi, "Anthropometric comparison of nasal indices between Andoni and Okrika tribes of Rivers State, Nigeria," International Journal of Medicine and Medical Sciences, vol. 1, no. 4, pp. 135-137, 2009.

[17] G. Staka, F. Dragidella, and M. Disha, "Anthropometric studies of nasal index of the Kosovo Albanian population," Antrocom Online Journal of Anthropology, vol. 8, no. 2, pp. 457-462, 2012.

[18] Z. Heidari, H. Mahmoudzadeh-Sagheb, T. Khammar, and M. Khammar, "Anthropometric measurements of the external nose in 18-25-year-old Sistani and Baluch aborigine women in the southeast of Iran," Folia Morphologica, vol. 68, no. 2, pp. 88-92, 2009. 

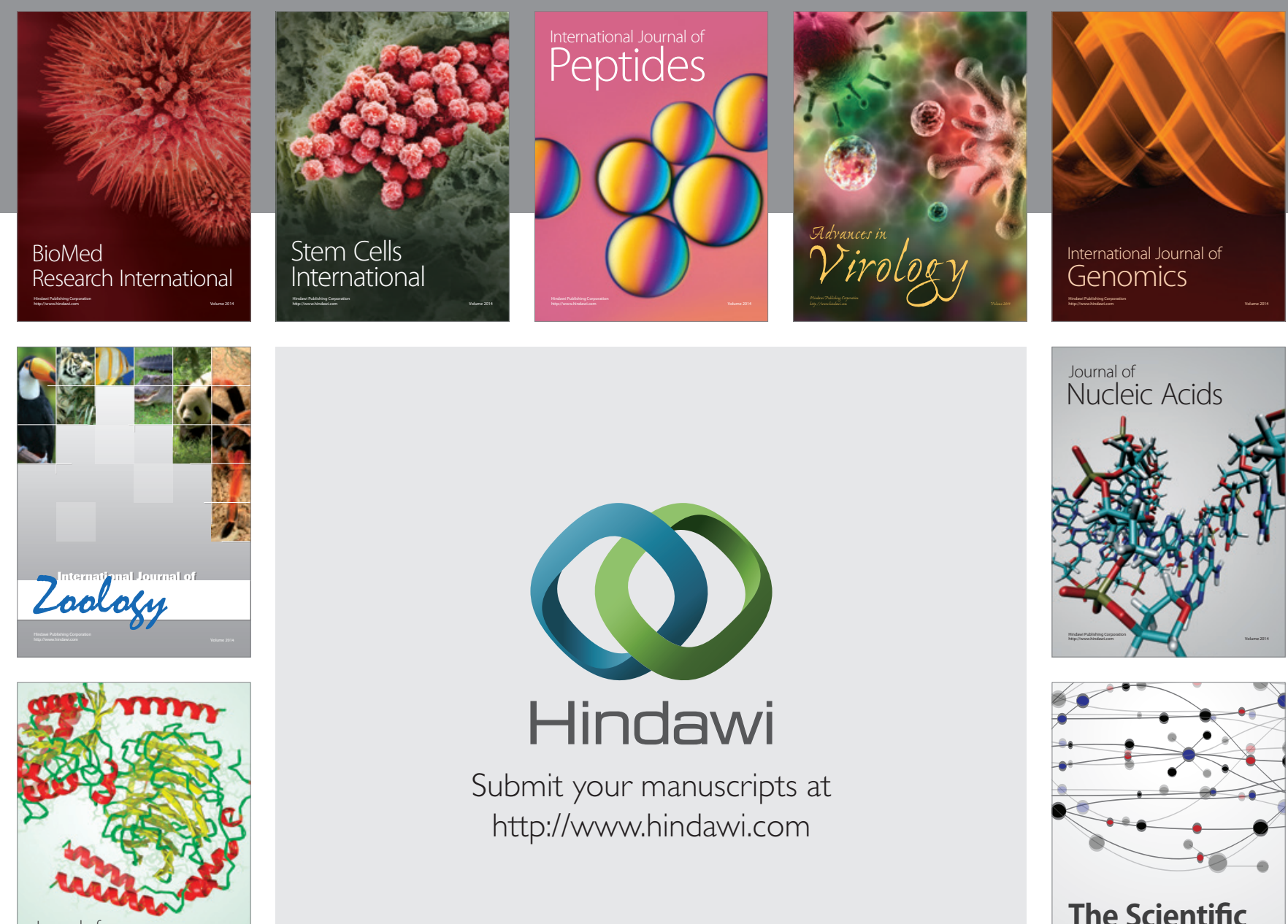

Submit your manuscripts at

http://www.hindawi.com

Journal of
Signal Transduction
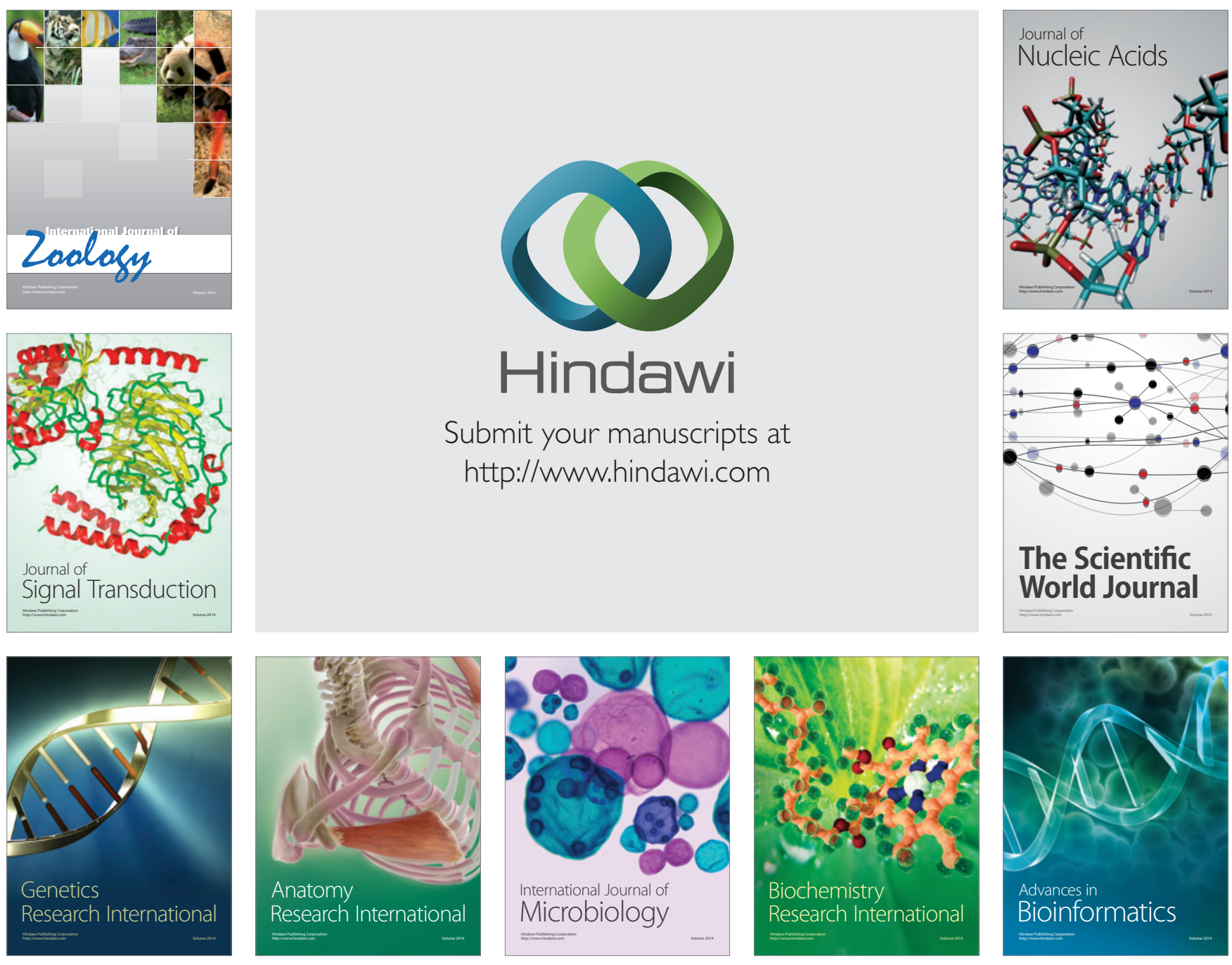

The Scientific World Journal
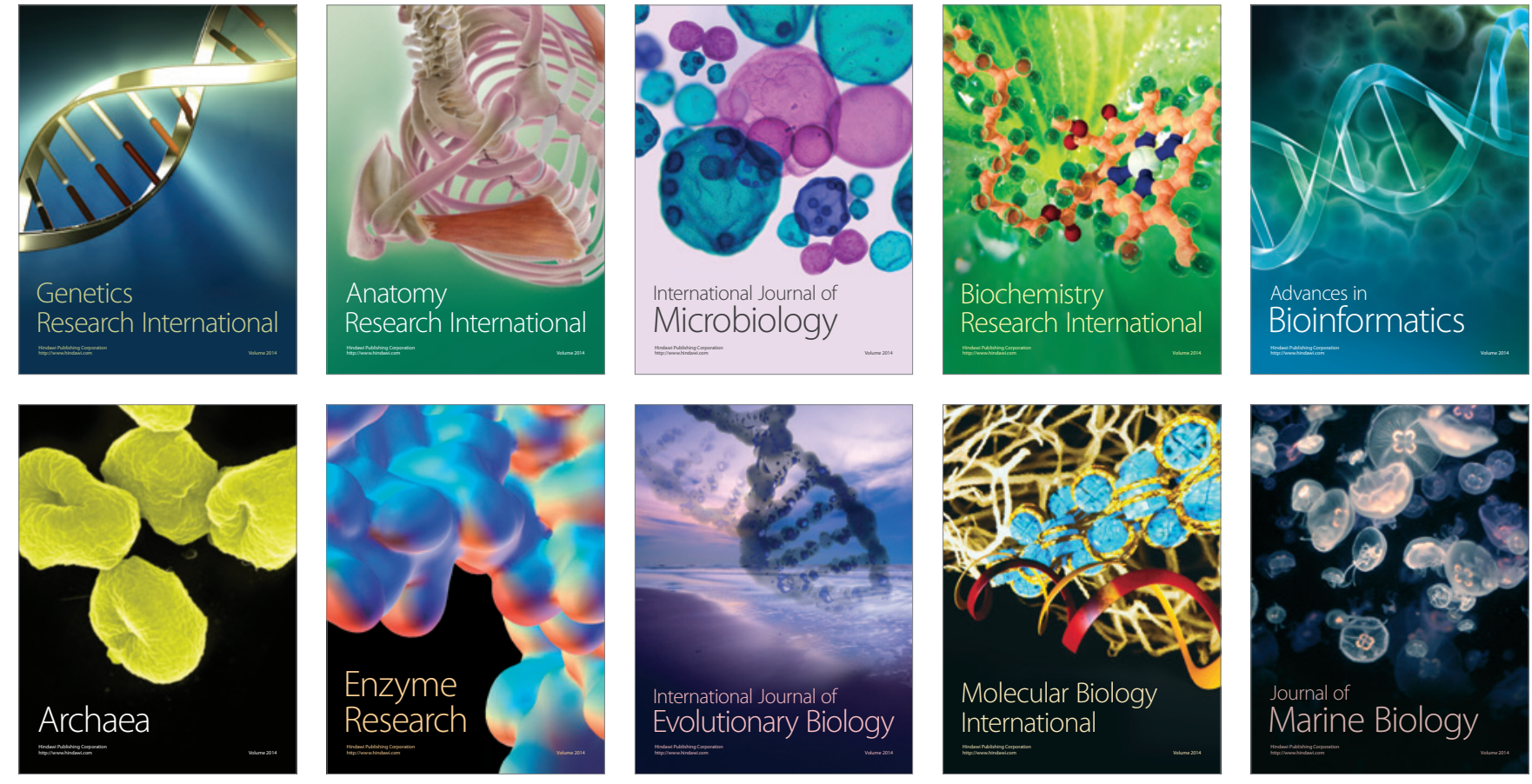